\title{
Acetate Production from Cafeteria Wastes and Corn Stover Using a Thermophilic Anaerobic Consortium: A Prelude Study for the Use of Acetate for the Production of Value-Added Products
}

\author{
Aditi David ${ }^{1}$, Abhilash Kumar Tripathi ${ }^{1}$ and Rajesh Kumar Sani ${ }^{1,2, * \mathbb{C}}$ \\ 1 Department of Chemical and Biological Engineering, South Dakota School of Mines and Technology, \\ Rapid City, SD 57701, USA; aditi.david@mines.sdsmt.edu (A.D.); \\ abhilashkumar.tripathi@mines.sdsmt.edu (A.K.T.) \\ 2 BuG ReMeDEE Consortium, South Dakota School of Mines and Technology, Rapid City, SD 57701, USA \\ * Correspondence: Rajesh.Sani@sdsmt.edu
}

Received: 5 February 2020; Accepted: 28 February 2020; Published: 2 March 2020

\begin{abstract}
Efficient and sustainable biochemical production using low-cost waste assumes considerable industrial and ecological importance. Solid organic wastes (SOWs) are inexpensive, abundantly available resources and their bioconversion to volatile fatty acids, especially acetate, aids in relieving the requirements of pure sugars for microbial biochemical productions in industries. Acetate production from SOW that utilizes the organic carbon of these wastes is used as an efficient solid waste reduction strategy if the environmental factors are optimized. This study screens and optimizes influential factors (physical and chemical) for acetate production by a thermophilic acetogenic consortium using two SOWs - cafeteria wastes and corn stover. The screening experiment revealed significant effects of temperature, bromoethane sulfonate, and shaking on acetate production. Temperature, medium $\mathrm{pH}$, and $\mathrm{C}: \mathrm{N}$ ratio were further optimized using statistical optimization with response surface methodology. The maximum acetate concentration of $8061 \mathrm{mg} \mathrm{L}^{-1}$ (>200\% improvement) was achieved at temperature, $\mathrm{pH}$, and $\mathrm{C}: \mathrm{N}$ ratio of $60^{\circ} \mathrm{C}, 6,25$, respectively, and acetate accounted for more than $85 \%$ of metabolites. This study also demonstrated the feasibility of using acetate-rich fermentate (obtained from SOWs) as a substrate for the growth of industrially relevant yeast Yarrowia lipolytica, which can convert acetate into higher-value biochemicals.
\end{abstract}

Keywords: acetogenic; thermophilic consortium; solid organic wastes; food and paper waste; Yarrowia lipolytica

\section{Introduction}

The need for sustainable energy generation in recent years has increased interest in microbial processes for the production of fuels and value-added products. Concurrently, the search for finding alternative low-cost substrates has also increased and the use of substrates that create direct competition with the food resources has been discouraged [1]. Commonly used substrates for microbial fermentation are simple sugars such as glucose and sucrose. Solid organic wastes (SOWs) such as food and paper waste, and agricultural wastes (such as corn stover) produced by anthropogenic activities, are abundant substrates that can be converted to intermediate or end-use bioproducts using microbial metabolism [2,3]. An enriched microbial consortium consisting of different microbial groups with diverse functions can degrade these SOWs into value-added end products or platform chemicals. Within the microbial consortium, hydrolytic enzymes produced by microbes convert the complex substrates into simpler sugars and organic acids. These intermediate organic acids often called as 
volatile fatty acids (VFAs) can be further utilized for microbial production of higher-value chemicals and thus can replace sugar substrates in industrial fermentations. VFAs are attractive substrates because they can be produced from a variety of organic wastes fermentation [4]. Therefore, the use of VFAs as carbon sources seems to be a feasible strategy for cost-effective microbial productions. Acetic acid or acetate is the most desirable VFA as it can serve as an alternate and sole source of carbon for microorganisms and can be used at comparatively higher concentrations to replace sugar substrates. The global demand of acetic acid is 14.3 billion pounds per year and it can be employed in the production of photographic film (cellulose acetate), wood glue (polyvinyl acetate), and synthetic fibers (triacetate cellulose) used for textile, carpets, and cigarette filters, among other products $[5,6]$. In addition to anaerobic fermentation by the acetogenic microbial consortium, acetic acid is also produced using chemical processes (e.g., methanol carbonylation, ethylene oxidation, and alkane oxidation) [7]. In the United States, the price of acetate ( $\$ 350-\$ 450$ per ton) is lower than the price of glucose (\$500 per ton) [8]; however, it is possible to obtain high titers of acetate inexpensively using renewable, and abundant feedstocks such as SOWs.

The microbial consortium carrying out thermophilic anaerobic digestion (TAD) comprise a significant fraction of acetogenic (acetate-producing) bacteria such as Acetomicrobium, Clostridium, and Acetobacter sp. which can convert SOW to acetate more rapidly and without any chemical or physical pretreatment [9]. The use of a TAD system is advantageous because the high-temperature fermentation process increases acetate end product formation and prevents the formation of other VFAs such as butyrate [10]. Thermophilic bacteria are also reported to simultaneously utilize mixed hexose and pentose sugars which could be beneficial when the SOW used is a lignocellulosic substrate [10,11]. Thermophilic conditions have additional benefits of high substrate degradation rate, pathogen removal, and efficient heat utilization of SOWs. The thermophilic microbial consortium also harbors distinct microbial species that possess metabolic functions related to biomass degradation and utilization [12,13]. Therefore, a TAD system fed with SOWs can be rewired to an acetate-producing system by inhibition of methanogenesis. This results in simultaneous enrichment of a thermophilic acetogenic consortium (TAC) which primarily produces acetate.

Most prior studies have optimized the factors leading to high total VFA productions $[4,14,15]$ for fuels and chemical applications. All these research endeavors are important considering that raw material alone constitutes $40 \%-80 \%$ of biofuel production costs. Biofuels made from VFAs derived from waste organic biomass potentially offer significant economic advantages [16]. To reduce production costs, some pure culture studies have been conducted and reviewed using SOWs [17-19]. However, the literature is limited regarding thermophilic anaerobic fermentation processes using mixed consortia that would use SOWs and produce a higher fraction of acetate (in the VFA pool). Though the control of metabolite is difficult in mixed culture fermentations compared to pure culture counterparts, however, mixed culture fermentations are advantageous due to the absence of sterilization requirements, a stable operation when designed on proper ecological selection principles, the potential for stable continuous operation, and adaptive capacity to variations in feed or conditions [20]. If optimized, mixed culture fermentation processes have a great chance to outcompete pure culture fermentations [17]. In addition, the production of a higher fraction of a single VFA (i.e., acetate in this study) is desirable for simplifying downstream recovery processes. Among the different VFAs, acetic acid has the highest market size, with 3,500,000 tons/y and a price per ton of $\$ 800$ [21]. The production of predominant acetate together with methane in extreme-thermophilic $\left(70{ }^{\circ} \mathrm{C}\right)$ mixed culture fermentation was first studied by Zhang et al. [12]. However, they used pure glucose as a substrate to achieve $>90 \%$ acetate in the fermentate's metabolite pool. In contrast, our study uses completely SOWs to produce acetate-rich fermentate. Knowledge of environmental factors affecting the acetate production from thermophilic acetogenic consortium is of considerable importance for the efficient conversion of SOWs into acetic acid at an industrial scale. Therefore, this work aims at developing a microbial consortium and maximizing acetate production using two SOWs — cafeteria (food and paper) wastes and corn stover-as a substrate. Initial screening experiments were conducted using two-level factorial design to screen for most 
influential parameters affecting the conversion of cafeteria and corn stover waste into acetic acid. Further, optimization of the process conditions, i.e., incubation temperature, $\mathrm{pH}$, and $\mathrm{C}: \mathrm{N}$ ratio, was done to understand their impact on acetic acid production at individual and interactive levels using statistical optimization with response surface methodology (RSM). Statistical optimization is a very effective tool in determining the process parameter values for increasing the desired product yield because it takes into account the interaction effects of the process parameters tested [22,23].

Various industrially relevant microorganisms can naturally utilize acetic acid and convert it into valuable bioproducts [24-28]. Advancement in the field of microbial genetics and metabolic engineering has furthered the range of bioproducts synthesized and substrates that can be utilized by microorganisms [29-31]. Research efforts have also been directed toward increasing the substrate uptake and its utilization. This is important to achieve higher bioproduct yields and productivity and, therefore, can improve the overall economics of industrial microbial processes. An industrially relevant host organism is the oleaginous yeast-Yarrowia lipolytica - which has gained a lot of attention recently for the production of lipids using various pure substrate (e.g., glucose, fructose, lactose, sucrose, glycerol, and xylose) and raw feedstocks (e.g., olive oil mill waste, whey, waste cooking oil, and animal fats) $[26,32]$. Oleaginous yeasts have a distinctive ability to convert certain organic acids directly to acetyl-CoA — the central intermediate of lipid biosynthesis-by acetyl coenzyme A synthetase. Acetyl-CoA is subsequently utilized in fatty acid (FA) synthesis and results in lipid accumulation [33]. Recent studies have also explored the potential of native and engineered Y.lipolytica to synthesize products other than lipids including itaconic acid [34], erythritol [35], citric acid [36], carotenoids [37], and polyhydroxyalkanoates [38]. So far, most studies on bioproduct synthesis by oleaginous microorganisms like Yarrowia lipolytica have been carried out with glucose as a carbon source. Published literature on volatile fatty acids (derived from different SOWs) as a sole carbon source for this yeast is scarce and no previous study has attempted to convert these low-cost volatile fatty acids into itaconic acid (a dicarboxylic acid), which is industrial chemical serving as a precursor of polymers used in plastics, adhesives, and coatings. It is also one of the "top 12" building block chemicals listed by the United States Department of Energy [39]. We are currently engineering a Yarrowia lipolytica strain to increase its ability to uptake acetate as well as upregulate the metabolic pathways that increase acetate assimilation and divert its metabolic flux toward itaconic acid production (unpublished work). For the current study, we studied the growth of the wild-type Y.lipolytica strain as a proof-of-concept for growing the engineered strain on the acetate-rich-fermentate in our future work. So, in addition to optimizing acetate production through anaerobic co-fermentation of cafeteria waste and corn stover, this study analyzes the feasibility of using this acetate-rich fermentate for growth of Y.lipolytica.

\section{Materials and Methods}

\subsection{Substrate}

Mixed SOWs (corn stover and cafeteria wastes) were used as substrates for all optimization experiments. Corn stover was kindly provided by Dr. K. Muthukumarappan from South Dakota State University, Brookings, SD. It was crushed using a blender and sieved through sieve between 15- and 10- $\mathrm{mm}$ pores before being used as a substrate. Cafeteria wastes consisting of paper and food wastes were obtained from the South Dakota of Mines and Technology (SDSMT) cafeteria. The composition of cafeteria waste varies depending on many factors such as region and season. So to reduce some of this bias, cafeteria wastes were collected on 3 separate days over a span of 3 months, homogenized, and reduced in size using a mechanical mixer and stored at $-20^{\circ} \mathrm{C}$ until use.

\subsection{Growth Medium and Experimental Set-Up}

A modified basal anaerobic medium was used for inoculum development and comprised of $(\mathrm{g} / \mathrm{L})$ : $\mathrm{K}_{2} \mathrm{HPO}_{4}, 0.3 ; \mathrm{KH}_{2} \mathrm{PO}_{4}, 0.3 ; \mathrm{NaCl}, 0.1 ; \mathrm{CaCl}_{2}, 0.05 ; \mathrm{NH}_{4} \mathrm{Cl}, 1.0 ; \mathrm{MgCl}_{2} \cdot 6 \mathrm{H}_{2} \mathrm{O}$ 0.5; $\mathrm{KCl}, 0.3 ;$ cysteine $\mathrm{HCl}$, 0.5 ; yeast extract, 0.05 and $\mathrm{Na}_{2} \mathrm{~S} \cdot 9 \mathrm{H}_{2} \mathrm{O}, 0.003$. $\mathrm{NaHCO}_{3}$ and Nitsch trace element solution were added 
to the medium to a final concentration of $20 \mathrm{mM}$ and $2.5 \mathrm{~mL}$ per liter, respectively. All the experiments were performed in duplicates in $500 \mathrm{~mL}$ serum bottles with $200 \mathrm{~mL}$ working volume consisting of $10 \%$ $v / v$ inoculum in anaerobic basal medium. The serum bottle reactors were autoclaved at $121^{\circ} \mathrm{C}$ and 15 psi for $20 \mathrm{~min}$ prior to inoculation. A $50 \mathrm{mM}$ solution of 2-bromoethanesulfonate (BES) was added to inhibit methanogenesis and enhance acetate production in different experimental runs according to the design of experiments. Following the addition of BES and inoculum, the serum bottle reactors were sealed with butyl rubber stoppers, crimped with aluminum crimps, and purged with nitrogen gas for $20 \mathrm{~min}$ to establish anaerobic conditions. They were incubated at different temperatures and in the presence or absence of shaking at $100 \mathrm{rpm}$ according to the design of experiments.

\subsection{Inoculum Development}

The inoculum used was a combination of two different types of anaerobic sludge collected from the Wastewater Reclamation Plant (Rapid City, SD, USA) and from a lab-scale anaerobic digester fed with food, paper, and lignocellulosic wastes (at the Chemical and Biochemical Engineering Department, SDSMT, Rapid City, SD, USA). The inoculum was prepared by mixing the two anaerobic sludges in equal amounts $(50 / 50 \mathrm{v} / \mathrm{v})$ and adjusting the $\mathrm{pH}$ to 6 with $1 \mathrm{M} \mathrm{HCl}$ while flushing with $\mathrm{N}_{2}$ to ensure anaerobic conditions. The inoculum was sieved through a $2 \mathrm{~mm}$ net after collection to remove large particles. The acetogenic consortia were developed and maintained in the lab using sub-culturing techniques as described by David and coll. (2018) [40]. Briefly, one-gram volatile solids (VS) of mixed SOW (containing equal amounts of corn stover and cafeteria wastes) was added to the modified anaerobic basal medium and the bottles were incubated at $60^{\circ} \mathrm{C}$ and $100 \mathrm{rpm}$. When acetate production reached a stable level, $10 \%(v / v)$ of the actively growing anaerobic culture was transferred into fresh basal media $(200 \mathrm{~mL})$ containing another $1 \mathrm{~g}$ of mixed waste. After 10 serial transfers, a thermophilic acetogenic consortium was obtained that produced acetate using corn stover and cafeteria wastes as carbon and energy source. All experiments and chemical analyses were done in duplicates and the value presented is an average of the two values from the duplicate set up. The microbial community analysis of the thermophilic consortium while shifting from biogas production to primarily acetate production is being studied using Illumina sequencing and will be part of a separate manuscript (in preparation).

\subsection{Analytical Methods}

Total solids (TS) and volatile solids (VS) of the substrate and inoculum were measured according to APHA standard methods [41]. The cellulose, hemicellulose, and lignin content were measured according to NREL analytical methods [42]. Elemental analysis was done by Atlantic Microlab, Norcross, GA. Liquid samples from the serum bottle reactors were analyzed for three major volatile fatty acids (VFAs) (acetate, propionate, and butyrate) at regular time intervals over a course of 8 days or until the acetate production ceased increasing. The liquid samples were centrifuged at 10,000 rpm for $10 \mathrm{~min}$ to remove suspended solids and biomass prior to VFA measurement. VFA concentrations were determined using HPLC equipped with Aminex HPX-97 H column with $0.005 \mathrm{~N}$ sulfuric acid as the mobile phase. Acetate percent was calculated by dividing the concentration of acetate $(\mathrm{mg} / \mathrm{L})$ in the reactor liquid by the total concentration of the measured VFAs (i.e., the sum of acetate, propionate, and butyrate concentrations in $\mathrm{mg} / \mathrm{L}$ ). Carbon to nitrogen ratio was calculated using the following equation $[40,43]$ :

$$
\mathrm{C}: \mathrm{N}=\frac{(\mathrm{VS} * \mathrm{TOC})_{C F W}+(\mathrm{VS} * \mathrm{TOC})_{C S}}{(\mathrm{VS} * \mathrm{TN})_{C F W}+(\mathrm{VS} * \mathrm{TN})_{C S}}
$$

where $\mathrm{TOC}=$ total organic carbon $(\% \mathrm{VS})$ and $\mathrm{TN}=$ total nitrogen $(\% \mathrm{VS})$ 


\subsection{Design of Experiment for Optimization of Acetate Production}

\subsubsection{Selection of Influential Factors}

Ten factors that could influence acetate fermentation and growth of the acetogenic consortium were selected and tested using two-level factorial design in Design Expert Version 12.0.6.0 (Stat-Ease Inc., Minneapolis, Minnesota, MN, USA) statistical software. In a two-level factorial experiment each independent variable, i.e., a "factor" is investigated at two discrete possible values or "levels". This is beneficial for estimating the main effects as well as the interaction effects of the factors tested. The 10 factors chosen are shown in Table 1. Thirty-two different experimental runs were performed. The factors included physical parameters (temperature, shaking), chemical factors ( $\mathrm{pH}$ and $\mathrm{C}: \mathrm{N}$ ratio), and inorganic medium components $\left(\mathrm{NaHCO}_{3}, \mathrm{NH}_{4} \mathrm{Cl}, \mathrm{MgCl}_{2} \cdot 6 \mathrm{H}_{2} \mathrm{O}\right.$, and $\left.\mathrm{KCl}\right)$. The impact of BES (methanogen inhibitor) and $\mathrm{Na}_{2} \mathrm{~S} .9 \mathrm{H}_{2} \mathrm{O}$ (to give basal media reducing power) addition was also investigated. With a signal-to-noise ratio of 3 , the power obtained for the statistical design was $99.9 \%$. This was greater than the minimum recommended $(>80 \%)$ for the effects that were to be detected. A low substrate load was used to dilute the inhibitory molecules that may be present in either cafeteria waste or corn stover, and that could potentially impact acetate fermentation by the newly developed consortium. Therefore, two-gram VS was used as a substrate for all the runs of this screening experiment. The factors that positively affected acetate concentration in the test runs were either selected for further optimization through RSM or were incorporated in all the RSM runs.

Table 1. Factors chosen for the two-level factorial design.

\begin{tabular}{cccccccc}
\hline Factor & Name & Units & Type & Minimum $^{\text {a }}$ & Maximum $^{\text {a }}$ & Mean & Std. Dev. \\
\hline $\mathrm{A}$ & Temperature & ${ }^{\circ} \mathrm{C}$ & Numeric & 45.00 & 60.00 & 52.50 & 7.62 \\
$\mathrm{~B}$ & $\mathrm{pH}$ & & Numeric & 5.00 & 7.00 & 6.00 & 1.02 \\
$\mathrm{C}$ & $\mathrm{C} / \mathrm{N}$ ratio & $\mathrm{g} \mathrm{VS}$ & Numeric & 15.00 & 25.00 & 20.00 & 5.08 \\
$\mathrm{D}$ & Shaking & $\mathrm{RPM}$ & Categoric & Yes & No & Levels ${ }^{\mathrm{b}}:$ & 2.00 \\
$\mathrm{E}$ & $\mathrm{BES}$ & & Categoric & Yes & No & Levels $^{\mathrm{b}}:$ & 2.00 \\
$\mathrm{~F}$ & $\mathrm{NaHCO}_{3}$ & $\mathrm{~g} / \mathrm{L}$ & Numeric & 2.00 & 4.00 & 3.00 & 1.02 \\
$\mathrm{G}$ & $\mathrm{NH}_{4} \mathrm{CL}$ & $9 / \mathrm{L}$ & Numeric & 1.0000 & 3.00 & 2.00 & 1.02 \\
$\mathrm{H}$ & $\mathrm{MgCl}_{2} \cdot 6 \mathrm{H}_{2} \mathrm{O}$ & $\mathrm{g} / \mathrm{L}$ & Numeric & 0.5000 & 1.0000 & 0.7500 & 0.2540 \\
$\mathrm{~J}$ & $\mathrm{KCL}_{\mathrm{K}}$ & $\mathrm{g} / \mathrm{L}$ & Numeric & 0.3000 & 0.6000 & 0.4500 & 0.1524 \\
\hline
\end{tabular}

${ }^{a}$ Minimum and maximum values presented here were the two levels selected for the experimental design. ${ }^{\mathrm{b}}$ The three categoric variables (Shaking, BES, $\mathrm{Na}_{2} \mathrm{~S} .9 \mathrm{H}_{2} \mathrm{O}$ ) were also tested at two levels depicted as "Yes" and "No" which indicated their presence and absence, respectively.

\subsubsection{Response Surface Methodology for Statistical Optimization of Influential Factors} for Acetate Production

RSM is a widely used statistical tool for modeling or analyzing a process in which the parameters which affect the process are called independent variables, whereas the responses are called dependent variables [44]. The objective for the RSM method is to optimize the response of interest which is affected by various variables, i.e., factors incorporated in the RSM design [45]. Response surface methodology (RSM) was used to optimize factors having a significant effect on acetate production by anaerobic fermentation of mixed SOW. Three factors (independent variables) - temperature, $\mathrm{pH}$, and $\mathrm{C}: \mathrm{N}$ ratio-were chosen for statistical optimization of acetate production (dependent variable) in this study. A substrate load of $5 \mathrm{~g}$ VS was used for all the experimental runs. A $2^{3}$ factorial central composite design with 14 non-center points and six replications at the center points $(\alpha=1.68)$ yielded a total of 20 experimental runs. Each factor/variable was set to 5 levels: $+\alpha$ and $-\alpha$ (axial points), +1 and -1 (factorial points), and the center point (Table 2). The Design Expert (Version 12.0.6.0) statistical software was used to analyze the results of the experimental design. Response was recorded in terms of acetate concentration in $\mathrm{mg} \mathrm{L}^{-1}$. Response data generated by the experimental runs are 
recorded in Table 3. It was subjected to analysis of regression through RSM to solve multivariate equations. The behavior of the system was explained by the following quadratic equation:

$$
\mathrm{Y}=\beta_{0}+\sum \beta_{i} X_{i}+\sum \beta_{i i} X_{i}^{2}+\sum \beta_{i j} X_{i} X_{j}
$$

where $\mathrm{Y}$ is the predicted response (acetate concentration, $\mathrm{mgL}^{-1}$ ), $\mathrm{X}$ represents individual factors being considered in the design (in this case temperature, $\mathrm{pH}$, and $\mathrm{C}: \mathrm{N}$ ratio), $\beta_{0}$ is the intercept, $\beta_{\mathrm{i}}$ linear effect coefficient, $\beta_{\mathrm{ii}}$ is the quadratic effect coefficient, and $\beta_{\mathrm{ij}}$ is interaction effect coefficient. The significance of each effect was estimated by analysis of variance with $p$-values $<0.05$, i.e., above a $95 \%$ confidence interval. The Statistical Design Expert software was applied for multiple regression analysis and to create the plots of the obtained data. Each experiment was performed in triplicates and the data presented is mean of the triplicate values.

Table 2. Experimental range and levels of independent variables for response surface methodology design.

\begin{tabular}{ccccccc}
\hline Codes & Variables & \multicolumn{5}{c}{ Levels $^{\text {a }}$} \\
\hline & & -1.682 & -1 & 0 & 1 & 1.682 \\
\hline A & Temperature & 43.18 & 50 & 60 & 70 & 76.82 \\
B & pH & 2.64 & 4 & 6 & 6 & 9.36 \\
C & C:N ratio & 16.59 & 20 & 25 & 30 & 33.41 \\
\hline
\end{tabular}

${ }^{a}$ Each variable was tested at 5 discreet values, i.e., levels denoted as +1.682 and -1.682 (axial points), +1 and -1 (factorial points), and 0 (the center point).

\subsection{Growth of Yarrowia Lipolytica on SOW-Derived Acetate-Rich Anaerobic Fermentation Product}

The yeast strain Y.lipolytica strain Polf was used to demonstrate the feasibility of using acetate-rich fermentate derived from optimized anaerobic fermentation of SOWs. Y.lipolytica (American Type Culture Collection (ATCC) no. MYA 2613) was procured from American Type Culture Collection (ATCC), USA. It was maintained as a glycerol stock at $-80^{\circ} \mathrm{C}$ prior to growth study. The anaerobically fermented product of SOW was centrifuged at 10,000 rpm for $10 \mathrm{~min}$ to precipitate biomass and suspended/undigested solids. The acetate and other VFA concentrations were measured in the supernatant obtained after filtration through a $0.2 \mu \mathrm{M}$ membrane. This acetate-rich VFA supernatant was used as a substrate for Y.lipolytica's growth without additional nutrients. The final acetate concentrations of $2,4,6$, and $8 \mathrm{~g} \mathrm{~L}^{-1}$ were adjusted by diluting with sterile de-ionized (DI) water. The $\mathrm{pH}$ was adjusted to 6.0 and the growth experiments were conducted in $500 \mathrm{~mL}$ Erlenmeyer flasks with a $200 \mathrm{~mL}$ working volume of fermentate and inoculum.

Y.lipolytica was precultured from glycerol stocks by inoculating $200 \mathrm{~mL}$ of YPD broth $\left(20 \mathrm{~g} \mathrm{~L}^{-1}\right.$ peptone, $10 \mathrm{~g} \mathrm{~L}^{-1}$ yeast extract, $20 \mathrm{~g} \mathrm{~L}^{-1}$ glucose $)$ in Erlenmeyer flasks and incubated at $28^{\circ} \mathrm{C}(200 \mathrm{rpm})$ until the late exponential growth phase ( $24 \mathrm{~h}-26 \mathrm{~h}$ ). For growth study, this preculture was used to inoculate $200 \mathrm{~mL}$ VFA supernatant to a starting $\mathrm{OD}_{600}$ of 0.2. A control experiment with glucose $\left(2 \mathrm{~g} \mathrm{~L}^{-1}\right)$ as the sole carbon source was also set up. Growth of Y.lipolytica was assessed by measuring biomass density in terms of dry cell weight (DCW). DCW was determined by vacuum filtering $5 \mathrm{~mL}$ of culture in the stationary growth phase through a pre-dried and pre-weighed nitrocellulose filter, and the sample was washed several times. The samples were dried to a constant weight before analyzing DCW. All growth experiments were performed in triplicates. In the presence of high VFA concentration $\left(>6 \mathrm{~g} \mathrm{~L}^{-1}\right)$, the batch cultures were incubated for 20 days in order to accommodate for adaptation of the yeast (lag phase of growth) to unfavorable culture conditions. All other batch cultures having different concentrations of acetate were cultivated until a measurable biomass production was observed. 


\section{Results and Discussion}

\subsection{Substrate and Inoculum Characteristics}

The substrate and inoculum characteristics are shown in Table 3. The TS and VS concentrations of the cafeteria waste was $28.3 \% \pm 0.6 \%$ and $23.2 \% \pm 0.7 \%$, respectively, whereas corn stover contained $94.8 \% \pm 0.6 \%$ TS and $89.5 \% \pm 0.8 \%$ VS. The cellulose, hemicellulose, and lignin content of the corn stover used in this study was $39.4 \%, 32.1 \%$, and $12.8 \%$, respectively. The inoculum had the TS and VS content of $4.3 \% \pm 0.5 \%$ and $2.6 \% \pm 1 \%$, respectively. Sub-culturing the inoculum with the same wastes as used for the experimental batch runs allowed for acclimatization of the thermophilic microbial consortium which is favorable for achieving higher acetate production [46-49]. Though the cafeteria waste had lower VS/TS percentage, it consisted of a higher amount of easily biodegradable organic compounds which made it a more easily hydrolyzable substrate for acetate production compared to corn stover. The C:N ratio of cafeteria waste, however, was substantially lower than corn stover. Therefore, apart from being an abundant, easily accessible, and inexpensive substrate, corn stover with a considerably higher $\mathrm{C}: \mathrm{N}$ ratio was a suitable co-substrate for cafeteria waste. Using two substrates with a significant difference in their $C: N$ ratio allowed adjustment of the $C: N$ ratio to different values needed for the design of this study.

Table 3. Substrate and inoculum characteristics.

\begin{tabular}{cccc}
\hline Parameters & Cafeteria Waste & Corn Stover & Inoculum \\
\hline Total solids (TS, \%w/w) & $28.3 \pm 0.6$ & $94.8 \pm 0.6$ & $4.3 \pm 0.5$ \\
Volatile solids (VS, \%w/w) $^{\mathrm{b}}$ & $23.2 \pm 0.7$ & $89.5 \pm 0.8$ & $2.6 \pm 1$ \\
VS /TS (\%) & 81.9 & 94.4 & 60.4 \\
C:N b $^{\mathrm{b}}$ & $15: 1$ & $56: 1$ & 2.5 \\
Volatile fatty acids/alkalinity $_{\text {Lignin (\%) }}^{\text {a }}$ & $\mathrm{ND}$ & $\mathrm{ND}$ & 1.3 \\
Cellulose (\%) $^{\mathrm{a}}$ & $\mathrm{ND}$ & 12.8 & $\mathrm{ND}$ \\
Hemicellulose (\%) $^{\mathrm{a}}$ & $\mathrm{ND}$ & 39.4 & $\mathrm{ND}$ \\
\hline
\end{tabular}

$\overline{\mathrm{ND}}=$ Not determined; ${ }^{\mathrm{a}}$ Based on total solids of the sample; ${ }^{\mathrm{b}}$ Based on total weight of the sample.

\subsection{Optimization of Acetate Production}

The microbial consortium during anaerobic fermentation can produce various gaseous (methane, hydrogen, carbon dioxide) and liquid products (acetate, propionate, butyrate, ethanol, lactate) in addition to increasing their biomass. Therefore, to increase the production of acetate, several factors were studied to analyze their impact and find the optimum values for the most influential factors for enhanced acetate production.

\subsubsection{Selection of Influential Factors}

Based on previous work and the available literature [21,46,50], 10 factors that could influence acetate fermentation and growth of the acetogenic consortium were selected. The influence of these 10 factors, i.e., temperature, $\mathrm{pH}, \mathrm{C}: \mathrm{N}$ ratio, shaking (100 rpm), $\mathrm{BES}(50 \mathrm{mM}), \mathrm{NaHCO}_{3}, \mathrm{NH}_{4} \mathrm{Cl}_{\text {, }}$ $\mathrm{MgCl}_{2} \cdot 6 \mathrm{H}_{2} \mathrm{O}, \mathrm{KCl}$, and $\mathrm{Na}_{2} \mathrm{~S} \cdot 9 \mathrm{H}_{2} \mathrm{O}$, was investigated using two-level factorial design. Two-level factorials can be used for screening many factors to find the significant few [21,46]. Parameters, experimental runs, and response (acetate concentration) of the experimental design are shown in Supplementary Table S1. The acetate concentration ranged between $483 \mathrm{mg} \mathrm{L}^{-1}$ and $2148 \mathrm{mg} \mathrm{L}^{-1}$ for the different experimental runs. In order to check the influence of the aforementioned factors, half-normal plots and pareto charts were analyzed (Figure 1). Pareto charts indicated that out of 10 factors tested, three factors, i.e., temperature, BES, and shaking, had the most significant effect on acetate production. The analysis of variance (ANOVA) for the selected factorial model with these three significant factors is given in Supplementary Table S2 and the Fit statististics are given in Supplementary Table S3. 
(A)

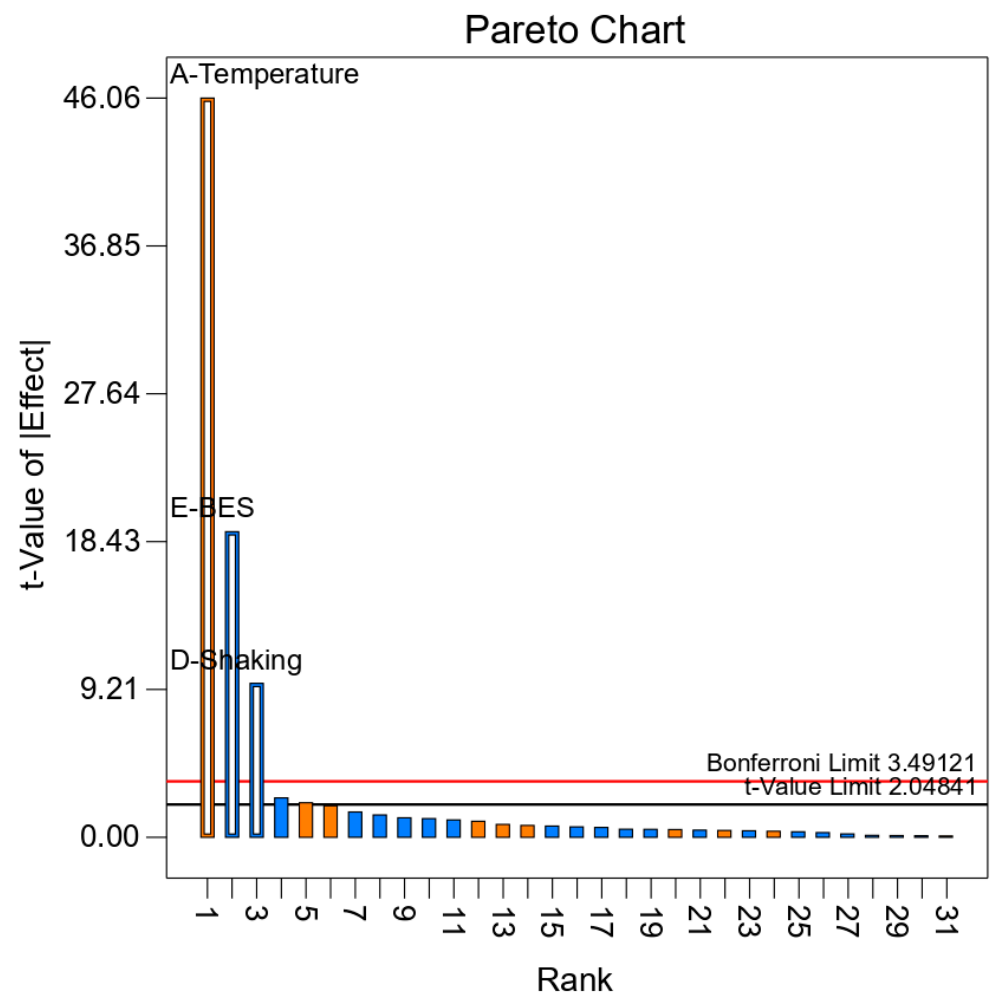

(B)

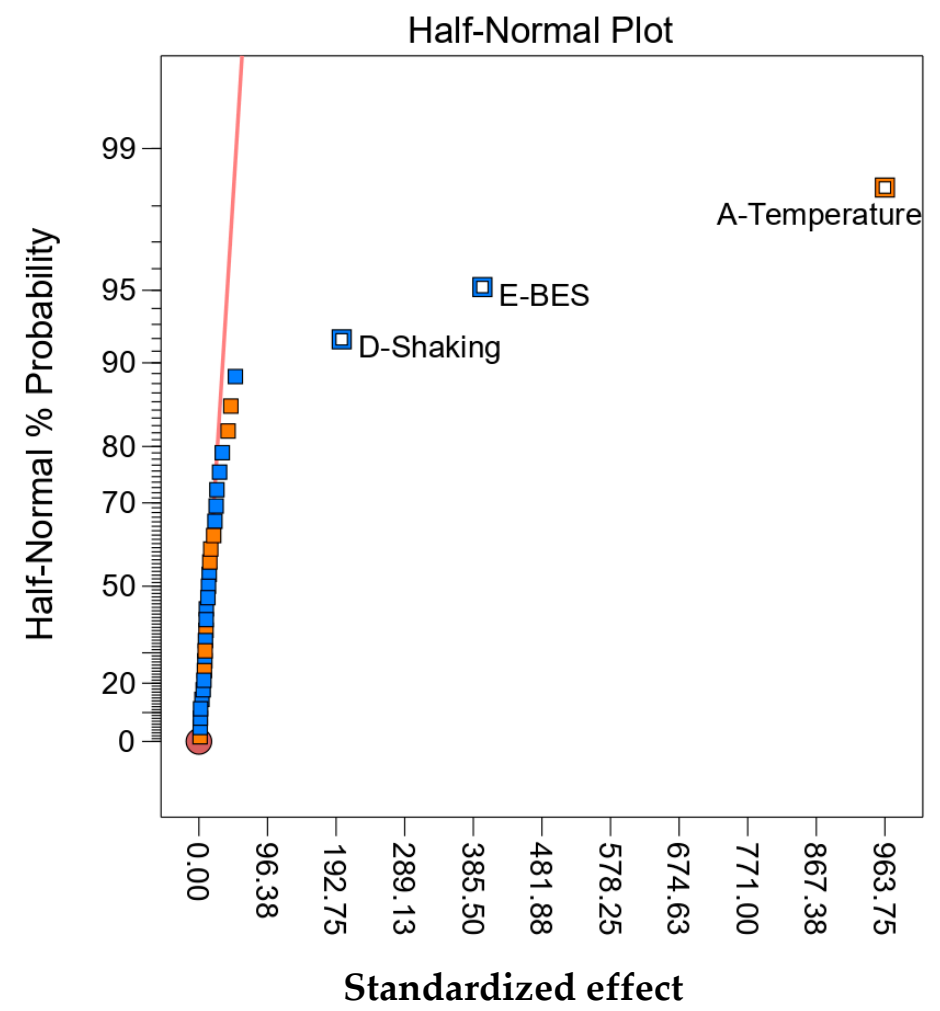

Figure 1. (A) Pareto charts and (B) half-normal plot for two-level factorial design. Above the Bonferroni limit (3.49121) the effects are significant. Effects in between the t-limit (2.04841) and Bonferroni limit may possibly be significant. Effects below the t-value limit are insignificant.

Average acetate production at an incubation temperature of $60{ }^{\circ} \mathrm{C}\left(1739.44 \mathrm{mg} \mathrm{L}^{-1}\right)$ was more than two-folds higher than the acetate production at $45^{\circ} \mathrm{C}\left(775.68 \mathrm{mg} \mathrm{L}^{-1}\right)$. Previous studies have also 
shown the prominent effect of temperature on acetate production $[4,12,51]$. For both the incubation temperatures, the presence of BES and shaking at $100 \mathrm{rpm}$ had a positive influence on acetate production. On average, the acetate production increased 1.4 and 1.2 times in the presence of BES and shaking, respectively. The effect of shaking was more pronounced at $45^{\circ} \mathrm{C}(1.3$ times improvement in average acetate concentration), while the effect of BES addition was more significant at $60^{\circ} \mathrm{C}(1.6$ times improvement in average acetate concentration). BES is a potent inhibitor of acetoclastic methanogenesis in thermophilic anaerobic systems [52,53]. It has previously shown to completely the inhibit activity of methanogens at a concentration of $50 \mathrm{mM}$ (also used in this study) [52,54]. Nevertheless, the literature shows contrasting effects of BES on inhibition of methanogens and VFA production which appear to be correlated to organic substrate loading $[21,46,54]$. In a recent study conducted by Lukitawesa and coll. (2020), BES addition showed more pronounced effects at lower substrate loading than higher substrate loading [46]. It was not surprising that the third most influential factor according to this study was shaking because previous studies have also reported enhanced acetate production under shaking conditions than static conditions $[51,55,56]$.

As the two temperatures chosen for the initial screening spanned a wide range $\left(45^{\circ} \mathrm{C}\right.$ and $\left.60^{\circ} \mathrm{C}\right)$, temperature was selected as one of the factors for further statistical optimization though the RSM design. $\mathrm{pH}$ and $\mathrm{C}: \mathrm{N}$ ratio were the other two factors chosen for better tuning of the optimum values as both have been reported to a exert strong effect on acetate production in previous studies $[21,46,57,58]$. The effect of $\mathrm{pH}$ and C:N ratio in the two-level factorial design in this study could have been masked by the stronger individual and combined effect of temperature, BES addition and shaking. To eliminate this masking effect and to better understand the effect of $\mathrm{pH}$ and $\mathrm{C}: \mathrm{N}$ ratio, $\mathrm{BES}$ and shaking conditions were kept the same in all the runs of the RSM design.

\subsubsection{Optimization of Influential Factors for Acetate Production Using RSM}

Based on the results of the above-mentioned screening experiment, the effects of temperature, different controlled $\mathrm{pH}$ values, and initial $\mathrm{C}: \mathrm{N}$ ratio were investigated in the second experiment (i.e., optimization using RSM). The response parameter (acetate in $\mathrm{m} \mathrm{L} \mathrm{L}^{-1}$ ) was the same as in the first experiment. A quadratic model based on the central composite design was developed in RSM to find optimum parameter values and study the combined effect of the variables-temperature, $\mathrm{pH}$, and C: $\mathrm{N}$ ratio. The central composite design resulted in 20 runs and the actual (experimentally observed) as well as predicted responses with the residuals are presented in Table 4 . The predicted and observed responses were analyzed by ANOVA. The main factor effects and two-factor interaction effects influencing the acetate production are shown in Table 5. A second-order regression equation provided the acetate concentration as a function of temperature, $\mathrm{pH}$, and $\mathrm{C}: \mathrm{N}$ ratio which is presented as a model equation for predicting acetate concentration. The model equation in terms of coded factors is as follows:

$$
\mathrm{Y}=0.2661 .5+256.82 \mathrm{~A}-49.76 \mathrm{~B}-8.64 \mathrm{C}-26.03 \mathrm{AB}+7.47 \mathrm{AC}+6.71 \mathrm{BC}-545.25 \mathrm{~A}^{2}-678.04 \mathrm{~B}^{2}-246.43 \mathrm{C}^{2}
$$

where $\mathrm{Y}, \mathrm{A}, \mathrm{B}$, and $\mathrm{C}$ are acetate $\left(\mathrm{mg} \mathrm{L}^{-1}\right)$, temperature, $\mathrm{pH}$, and $\mathrm{C}: \mathrm{N}$ ratio, respectively.

The coded equation is useful for identifying the relative impact of the factors by comparing the factor coefficients. The equation in terms of coded factors can be used to make predictions about the response (acetate in $\mathrm{mg} \mathrm{L}^{-1}$ ) for given levels of each factor. This equation was used to obtain contour plots and 3D response surface graphs which was used to predict optimum values of the three factors tested (Figure 2). These plots and graphs were created for the pair-wise combination of the two factors while keeping the third factor at its optimum value. 

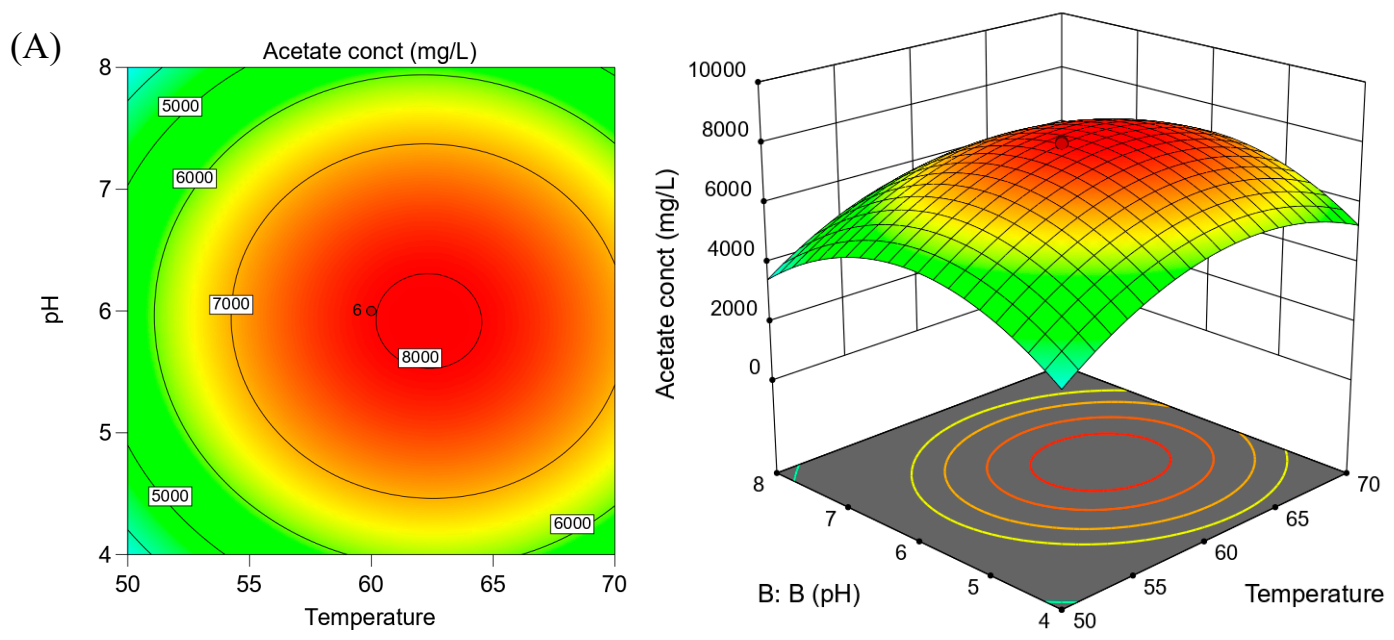

(B)
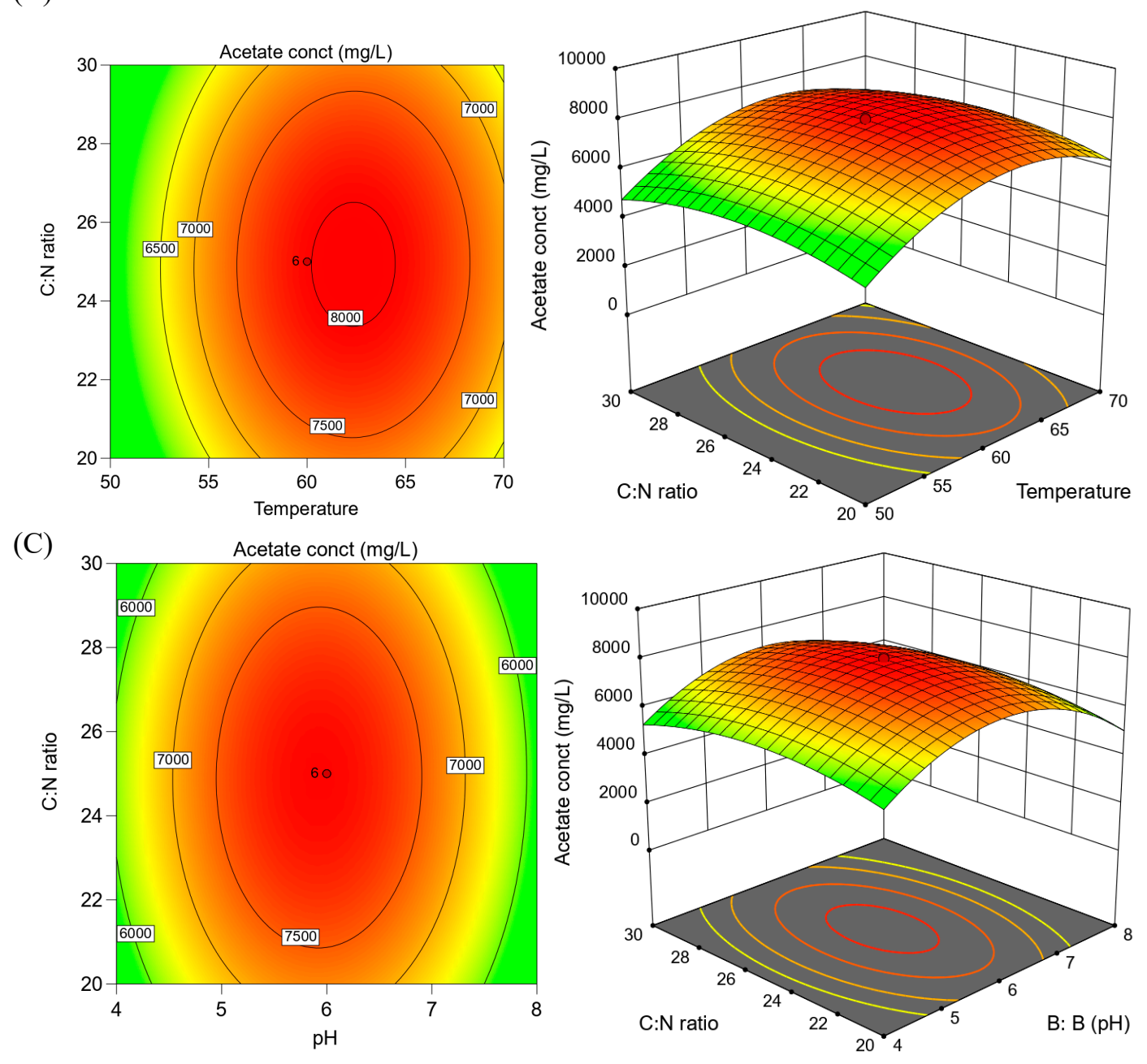

Figure 2. Three-dimensional response surface plots showing acetate concentration by thermophilic acetogenic consortium and interaction between: (A) $\mathrm{pH}$ and temperature; (B) C:N ratio and temperature; (C) $\mathrm{C}: \mathrm{N}$ ratio and $\mathrm{pH}$. The minimum and maximum values are represented by green and red color, respectively. The other colors represent values in between the minimum and maximum values. These plots and graphs were created for the pair-wise combination of the two factors while keeping the third factor at its optimum value. 
Table 4. Central composite design along with actual (experimental) and predicted values of the dependent variable.

\begin{tabular}{cccccc}
\hline Run Order & Temperature $\left({ }^{\circ} \mathbf{C}\right)$ & pH & C:N Ratio & \multicolumn{2}{c}{ Acetate Conct. $\left(\mathbf{m g ~ L}^{-\mathbf{1}}\right)$} \\
\hline 1 & $\mathbf{A}$ & $\mathbf{B}$ & $\mathbf{C}$ & Actual Value & Predicted Value \\
\hline & 60 & 6 & 25 & 8011.41 & 7983.16 \\
3 & 43.1821 & 6 & 25 & 1939.26 & 2060.80 \\
4 & 76.8179 & 6 & 25 & 4726.20 & 4652.27 \\
5 & 50 & 4 & 30 & 2929.86 & 2806.26 \\
6 & 60 & 6 & 25 & 8015.88 & 7983.16 \\
7 & 60 & 9.36359 & 25 & 2050.74 & 1978.79 \\
8 & 60 & 6 & 25 & 8061.42 & 7983.16 \\
9 & 70 & 4 & 30 & 4468.65 & 4548.17 \\
10 & 60 & 2.63641 & 25 & 2361.30 & 2480.86 \\
11 & 70 & 4 & 20 & 4706.98 & 4595.46 \\
12 & 70 & 8 & 20 & 4010.55 & 4100.48 \\
13 & 50 & 4 & 20 & 3015.96 & 2943.18 \\
14 & 60 & 6 & 33.409 & 5908.11 & 5848.53 \\
15 & 50 & 8 & 20 & 2873.79 & 2760.60 \\
16 & 60 & 6 & 16.591 & 5828.55 & 5935.74 \\
17 & 60 & 6 & 25 & 7997.34 & 7983.16 \\
18 & 60 & 6 & 25 & 7969.41 & 7983.16 \\
19 & 50 & 8 & 30 & 2626.32 & 2704.18 \\
20 & 70 & 8 & 30 & 4094.58 & 4133.69 \\
\hline
\end{tabular}

The analysis of variance (ANOVA) showed that the quadratic model was significantly based on $p$-values and an F-test (Table 5). The Model F-value of 753.01 implies the model is significant. There is only a $0.01 \%$ chance that an F-value this large could occur due to noise. Lack of fit F-value of 4.78 implies there is a $5.56 \%$ chance that a lack of fit F-value this large could occur due to noise. Lack of fit was not significant relative to the pure error which is good because we want the model to fit. The Model $p$-value of $<0.0001$ also indicated high model significance. P-values less than 0.05 indicate model terms are significant. In this case, $\mathrm{A}, \mathrm{B}, \mathrm{A}^{2}, \mathrm{~B}^{2}$, and $\mathrm{C}^{2}$ are significant model terms (Table 5). The Predicted $\mathrm{R}^{2}$ of 0.9985 was in reasonable agreement with the Adjusted $\mathrm{R}^{2}$ of 0.9972 (Supplementary Table S4). A low coefficient of variance value (C.V. \%) of 2.45 indicated adequate precision and applicability of the model to navigate the design space. Adequate precision (signal-to-noise ratio) of greater than four was desirable and the model had a ratio of 69.743. All these evaluations confirmed that the model can be used for the prediction of maximum acetate production using our thermophilic acetogenic consortium. In the surface response plot (Figure 3), the concentration of the data points near the straight line also indicates high correlation and precision.

Effects of $\mathrm{pH}$ and temperature are shown in Figure 2A. $\mathrm{pH}$ and temperature are key parameters during acidogenic fermentation as it impacts both microbial growth and metabolism [4]. At the lowest $\mathrm{pH}$ and reaction temperature, acetate production was low. As the $\mathrm{pH}$ and temperature increased, the VFA production also increased gradually to reach a maximum value; it then decreased. The optimal temperature and $\mathrm{pH}$ for VFA production in this study were $60^{\circ} \mathrm{C}$ and 6.0 , respectively. This finding is consistent with our previous study where a temperature of $60^{\circ} \mathrm{C}$ was found to be optimum for the thermophilic consortium carrying out anaerobic fermentation of food, paper, and lignocellulosic wastes [40]. The positive effect of slightly acid-neutral conditions on microbial metabolism and therefore on fermentative production has been demonstrated by previous studies as well. Jiang and coll. (2013) found that a pH value between 6 and 7 resulted in an increase of around $20 \%$ of the hydrolysis rate, and doubled the VFAs production in the batch reactor compared to the batch reactor with uncontrolled pH [59]. Similarly, Wang and coll. (2014) reported a 17.5 times increase in VFA production, and a 7.5 times increase in VFA yield at a $\mathrm{pH}$ value of six compared to a $\mathrm{pH} 4$ [60]. Eryildiz 
and coll. (2019) and Lukitavesa and coll. (2020) also studied the effect of three different pH $(4,5,6)$ on VFA production from citrus waste and reported highest VFA production and yield at $\mathrm{pH} 6[21,46]$.

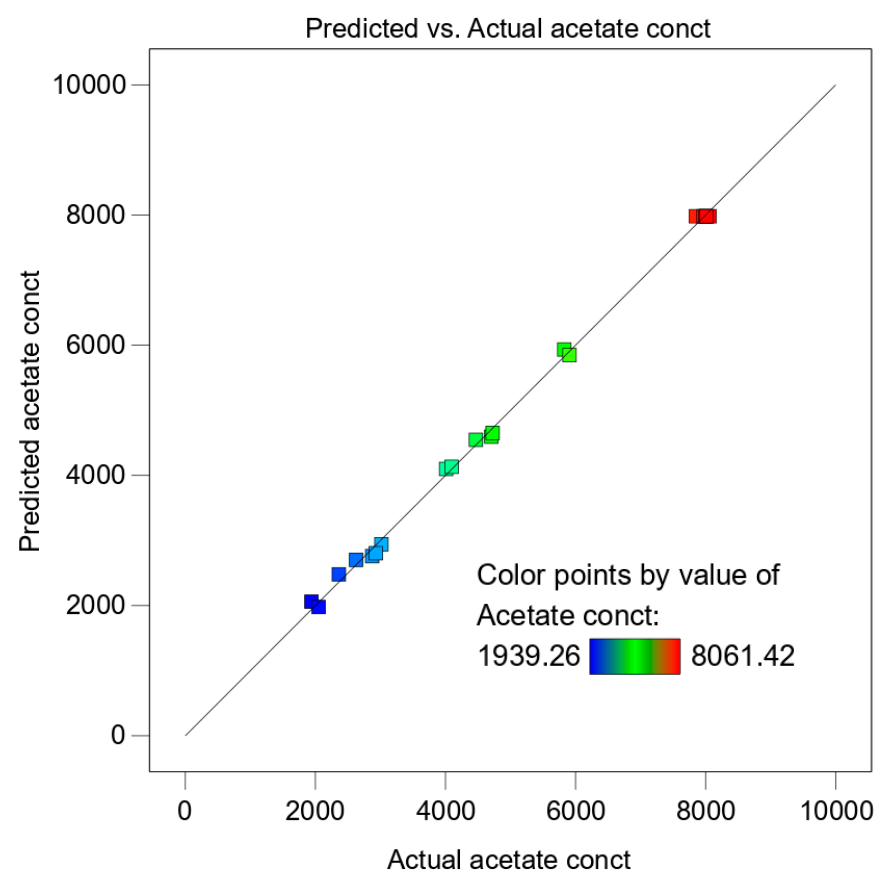

Figure 3. Surface response plot for predicted vs. actual values (acetate conct. in $\mathrm{mg} \mathrm{L}^{-1}$ ). The squares represent the experimental values obtained from the runs. The concentration of the data values near the straight line shows a high correlation and adequate precision. The minimum value is denoted by a blue color, whereas the maximum value is denoted by a red color. The rest of the colors represent a range between the minimum and maximum value.

Figure $2 \mathrm{~B}$ shows the interaction of $\mathrm{C}: \mathrm{N}$ ratio and temperature and Figure $2 \mathrm{C}$ reflects the interaction of C:N ratio and $\mathrm{pH}$. The RSM indicated that VFA production gradually increased with increasing $\mathrm{C}: \mathrm{N}$ ratio, whereas the increase in VFA was more abrupt with increasing temperature and $\mathrm{pH}$ up to $60{ }^{\circ} \mathrm{C}$ and 6, respectively. The $\mathrm{C}: \mathrm{N}$ ratio is an important parameter in anaerobic fermentation for VFA production and should be taken into consideration. The results obtained by Liu and coll. (2008) showed that the initial $\mathrm{C}: \mathrm{N}$ ratio was one of the most important factors influencing the distribution patterns of VFAs and the yield of total VFAs [61]. However, there is an optimal narrow range of C:N ratio beyond where there is no further increase in VFA production. This is because it is important for an optimum amount of nitrogen to be present in the feedstock to avoid either nutrient limitation (too low nitrogen) or ammonia toxicity (too high nitrogen) [61,62]. A C:N ratio of 25 was found to be optimum for acetate production in this study. Our results were similar to the results reported by Wang and coll. (2014) who discovered that, when the temperature is increased, an increase was required in the $\mathrm{C} / \mathrm{N}$ ratio in order to reduce the risk of ammonia inhibition, thus revealing the interactive effect between temperature and C:N ratio [62].

Many optimization studies have been conducted for increasing VFA production from various SOWs [21,46,58]; however, no prior statistical optimization studies (to the best of author's knowledge) aimed at optimizing acetate concentration in the VFA pool. This is of interest because acetate is the least inhibitory VFA to microbial growth and metabolism and, therefore, can be used in higher concentrations compared to other VFAs. In this study, acetate accounted for $45 \%-86 \%$ of the total VFAs in different experimental runs. The highest fraction of acetate $(\sim 86 \%)$ was observed in the runs giving the highest acetate concentration in terms of $\mathrm{mgL}^{-1}$. Maximum acetate concentration $\left(8061 \mathrm{mg} \mathrm{L}^{-1}\right)$ was obtained at $\mathrm{pH} 6$, temperature $60^{\circ} \mathrm{C}$, and a $\mathrm{C}: \mathrm{N}$ ratio of 25; thus, these conditions can be deemed as optimum conditions according to the developed model. Post-analysis model validation experiment 
produced $3423 \mathrm{mg} \mathrm{L}^{-1}$ and $8057 \mathrm{mg} \mathrm{L}^{-1}$ of acetate under optimized and unoptimized conditions, respectively. This marked a 2.4-fold increase in acetate levels. The post-analysis run gave a response value for acetate concentration that was within $>95 \%$ of the predicted value by the quadratic model indicating the usefulness, and accuracy of the model.

Table 5. Analysis of variance (ANOVA) for quadratic model developed for acetate production by the thermophilic acetogenic consortium.

\begin{tabular}{|c|c|c|c|c|c|c|}
\hline Source & Sum of Squares & df & Mean Square & F-Value & $p$-Value & \\
\hline Model $^{a}$ & $1.005 \times 10^{8}$ & 9 & $1.116 \times 10^{7}$ & 753.01 & $<0.0001$ & Significant $^{\mathrm{b}}$ \\
\hline A-A & $8.107 \times 10^{6}$ & 1 & $8.107 \times 10^{6}$ & 546.85 & $<0.0001$ & \\
\hline B-B & $3.043 \mathrm{E} \times 10^{5}$ & 1 & $3.043 \times 10^{5}$ & 20.53 & 0.0011 & \\
\hline$C-C$ & 9179.67 & 1 & 9179.67 & 0.6192 & 0.4496 & \\
\hline $\mathrm{AB}$ & 48795.83 & 1 & 48795.83 & 3.29 & 0.0997 & \\
\hline $\mathrm{AC}$ & 4017.07 & 1 & 4017.07 & 0.2710 & 0.6140 & \\
\hline $\mathrm{BC}$ & 3239.85 & 1 & 3239.85 & 0.2186 & 0.6502 & \\
\hline $\mathrm{A}^{2}$ & $3.856 \times 10^{7}$ & 1 & $3.856 \times 10^{7}$ & 2601.17 & $<0.0001$ & \\
\hline $\mathrm{B}^{2}$ & $5.963 \times 10^{7}$ & 1 & $5.963 \times 10^{7}$ & 4022.35 & $<0.0001$ & \\
\hline$C^{2}$ & $7.876 \times 10^{6}$ & 1 & $7.876 \times 10^{6}$ & 531.32 & $<0.0001$ & \\
\hline Residual & $1.482 \times 10^{5}$ & 10 & $14,824.24$ & & & \\
\hline Lack of Fit & $1.226 \times 10^{5}$ & 5 & $24,517.16$ & 4.78 & 0.0556 & Not significant \\
\hline Pure Error & 25656.60 & 5 & 5131.32 & & & \\
\hline Cor Total & $1.006 \times 10^{8}$ & 19 & & & & \\
\hline
\end{tabular}

\subsection{Growth of Yarrowia Lipolytica on Acetate-Rich Anaerobic Fermentation Product Derived from SOW}

Considering the industrial and environmental challenges associated with using low-cost waste as starting feedstocks for microbial biochemical production, we employed and developed an acetogenic consortium for a sustainable conversion of SOWs into mainly acetate (and a few other VFAs). The final aim is to use this acetate-rich fermentate as a sole carbon source for growth, metabolism, and biochemical production of itaconic acid by the selected host - Y.lipolytica. In this direction, cafeteria waste and corn stover derived fermentate was used to grow Y.lipolytica in batch cultures to evaluate the potential of the fermentate for practical application. Anaerobic fermentate was predominantly composed of short-chain (C2-C3) VFAs ( $90 \%$ of the total substrate) and small amounts of long-chain VFAs (C4-C6) were detected.

During the experimental observation period of 20 days, batch cultures with four different concentrations of the fermentate (adjusted to achieve acetate concentration of 2, 4, 6, and $8 \mathrm{~g} / \mathrm{L}$ ) showed an increase in biomass density (in term of DCW) with increasing acetate concentration. (Figure 4, Table 6). Since all the concentrations of acetate selected for this study were conducive for cell growth of Y.lipolytica, higher initial acetate concentrations could help achieve higher cell densities. Higher acetate concentration can be attained by increasing the organic load of SOW in the anaerobic fermentation process using the thermophilic acetogenic consortium and the optimized parameters of this study. However, an important parameter to be considered for analyzing economical and practical application is the growth yield coefficient, $\mathrm{Y}_{\mathrm{X} / \mathrm{S}}$, which appeared to decrease when higher concentrations of adjusted acetate levels $\left(6\right.$ and $\left.8 \mathrm{~g} \mathrm{~L}^{-1}\right)$ were used (Table 6).

It is established that higher total VFA concentration shows stronger inhibitory effects on growth, and the yeast would require a longer lag phase prior to effective cell growth [63]. According to Rodrigues and Pais (2000), high initial VFA concentrations inhibit cell growth by chemically interfering with the membrane transport of phosphate, thereby increasing ATP expenditure [64]. In this study, even though there was substantial biomass growth at all the concentrations tested, the lag phase differed (Table 6). The general trend was as expected, the lag phase increased with increasing adjusted acetate concentrations of the substrate. Previous studies have shown different upper limits for inhibitory 
VFA concentrations $[60,65,66]$. Different systems have their own levels of VFAs that can be considered "normal" for the reactor, and conditions that cause instability in one reactor do not cause problems in another reactor [67]. The inhibitory concentrations also vary with the type of VFA. Literature studies have shown that acetate has the least inhibitory effect on cell growth and metabolism compared to other common VFAs (propionic acid, butyric acid, valeric acid, iso-butyric acid, iso-valeric acid). In a study conducted by Gao and coll. (2017), Y.lipolytica showed a preference for acetate and faster utilization rates of acetate over other VFAs when a mixture of VFAs was used as a substrate. Slower utilization rates of other VFAs (propionate and butyrate) compared to acetate can be attributed to their different metabolic fates after intake.

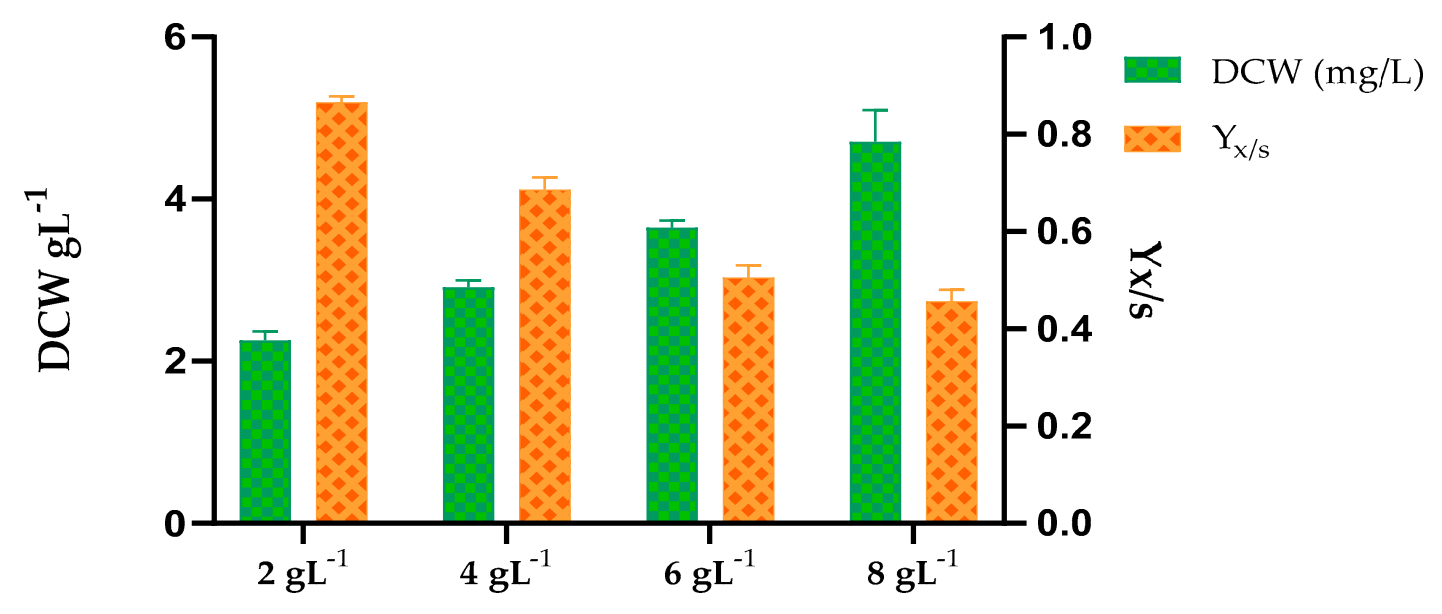

Adjusted acetate concentration

Figure 4. Comparison of dry cell weight $(\mathrm{DCW})$ and growth yield coefficient $\left(\mathrm{Y}_{\mathrm{X} / \mathrm{S}}\right)$ obtained during batch cultivation on different substrate loading of anaerobic fermentate derived from cafeteria waste and corn stover mixture.

Table 6. Biomass production of Y.lipolytica on solid organic wastes (SOW) (cafeteria waste and corn stover) fermentate.

\begin{tabular}{cccc}
\hline Adjusted Acetate Concentration & $\begin{array}{c}\mathbf{D C W}^{\mathbf{a}} \\
\mathbf{( g ~ L}^{-1} \mathbf{)}\end{array}$ & $\begin{array}{c}\mathbf{Y x} / \mathbf{s}^{\mathbf{b}} \\
\mathbf{( g ~ g}^{\mathbf{1}} \mathbf{)}\end{array}$ & $\begin{array}{c}\text { Lag Phase } \\
\mathbf{( h )}\end{array}$ \\
\hline $2 \mathrm{~g} \mathrm{~L}^{-1}$ & $2.257 \pm 109$ & $0.865 \pm 0.0127$ & $<3$ \\
$4 \mathrm{~g} \mathrm{~L}^{-1}$ & $2.864 \pm 0.153$ & $0.786 \pm 0.025$ & $<3$ \\
$6 \mathrm{~g} \mathrm{~L}^{-1}$ & $3.647 \pm 0.092$ & $0.505 \pm 0.036$ & 12 \\
$8 \mathrm{~g} \mathrm{~L}^{-1}$ & $4.705 \pm 0.394$ & $0.456 \pm 0.057$ & 24 \\
\hline${ }^{\mathrm{a}}$ DCW—dry cell weight; ${ }^{\mathrm{b}}$ Yx/s—growth yield coefficient.
\end{tabular}

\section{Conclusions}

The present study was conducted to screen the effects of physical and chemical factors and to optimize acetate production by anaerobic fermentation of two SOWs - cafeteria waste and corn stover. The screening of influential factors using two-level factorial design revealed that incubation temperature, BES addition, and shaking conditions (100 rpm) had the most significant effect on acetate production among the 10 factors tested. The ANOVA analysis confirmed that the selected model was significant. The statistical optimization experiment using RSM resulted in a maximum acetate production of $\sim 8000 \mathrm{mg} \mathrm{L}^{-1}$ at a temperature, $\mathrm{pH}$, and $\mathrm{C}: \mathrm{N}$ ratio of $60{ }^{\circ} \mathrm{C}, 6$, and 25 , respectively. It is noteworthy that the difference in the three levels selected by the central composite design for the $C: N$ ratio had a considerable difference among them and fine-tuning of this parameter can further improve acetate production as is observed in previous studies. So, further optimization with a narrow range of $\mathrm{C}: \mathrm{N}$ ratio can be done. Supplementation of methanogen inhibitor, BES, may not be needed if higher 
substrate loading is used as higher acetate and/or VFA production is known to inhibit methanogenesis. In the absence of acetoclastic methanogenesis, this can lead to further acetate accumulation.

This study also demonstrated the use of acetate-rich fermentate as a sole carbon source (without any nutrient addition) for the growth of an industrially relevant yeast selected for this study-Y.lipolytica - which can convert VFAs in the fermentation product (derived from cafeteria waste and corn stover) into higher-value-added products. According to the results of this study, different initial acetate concentrations exerted different inhibitory effects on cell growth which is mainly evident by the different duration of lag phase and biomass production (in terms of DCW). Higher initial acetate concentrations required longer lag phase though the biomass density was not affected significantly. Our future work is being directed toward engineering Y.lipolytica to improve acetate uptake and direct its carbon flux toward the heterologous expression of itaconic acid which has widespread industrial applications. Thus, developing an acetogenic consortium and optimizing VFA production for higher acetate concentrations was an important milestone in the direction of using low-cost waste substrate for the production of higher-value biochemicals using Y.lipolytica as a host organism. In addition, the acetate-rich fermentate can be used by other industrial microorganisms for the production of various by-products, the feasibility of which can be checked in future studies.

Supplementary Materials: The following are available online at http://www.mdpi.com/2076-2607/8/3/353/s1. Table S1: Parameters, experimental runs and response of two-level fractional factorial design used for screening of influential factors for acetate production by the developed acetogenic consortia, Table S2: Selected Two-level factorial design-Analysis of Variance (ANOVA), Table S3: Selected Two-level factorial design-Fit Statistics, Table S4: RSM Quadratic model-Fit statistics.

Author Contributions: Conceptualization, A.D. and R.K.S.; methodology, A.D.; software, A.D. and A.K.T.; validation, A.D., R.K.S., and A.K.T.; formal analysis, A.D. and A.K.T.; investigation, A.D.; resources, R.K.S.; data curation, A.D.; writing-original draft preparation, A.D. and R.K.S.; writing-review and editing, A.K.T. and R.K.S.; visualization, A.D. and A.K.T.; supervision, R.K.S.; project administration, R.K.S; funding acquisition, R.K.S. All authors have read and agreed to the published version of the manuscript.

Funding: This research received no external funding.

Acknowledgments: The authors are grateful to Department of Chemical and Biological Engineering at the South Dakota School of Mines and Technology for providing financial support and instruments for completion of this work.

Conflicts of Interest: The authors declare no conflicts of interest.

\section{References}

1. Liu, N.; Santala, S.; Stephanopoulos, G. Mixed carbon substrates: A necessary nuisance or a missed opportunity? Curr. Opin. Biotechnol. 2020, 62, 15-21. [CrossRef] [PubMed]

2. Dhiman, S.S.; David, A.; Shrestha, N.; Johnson, G.R.; Benjamin, K.M.; Gadhamshetty, V.; Sani, R.K. Simultaneous hydrolysis and fermentation of unprocessed food waste into ethanol using thermophilic anaerobic bacteria. Bioresour. Technol. 2017, 244, 733-740. [CrossRef] [PubMed]

3. Dhiman, S.S.; David, A.; Braband, V.W.; Hussein, A.; Salem, D.R.; Sani, R.K. Improved bioethanol production from corn stover: Role of enzymes, inducers and simultaneous product recovery. Appl. Energy 2017, 208, 1420-1429. [CrossRef]

4. Strazzera, G.; Battista, F.; Garcia, N.H.; Frison, N.; Bolzonella, D. Volatile fatty acids production from food wastes for biorefinery platforms: A review. J. Environ. Manage. 2018, 226, 278-288. [CrossRef]

5. Erickson, B.; Nelson; Winters, P. Perspective on opportunities in industrial biotechnology in renewable chemicals. Biotechnol. J. 2012, 7, 176-185. [CrossRef]

6. Puls, J.; Wilson, S.A.; Hölter, D. Degradation of Cellulose Acetate-Based Materials: A Review. J. Polym. Environ. 2011, 19, 152-165. [CrossRef]

7. Pal, P.; Nayak, J. Acetic Acid Production and Purification: Critical Review Towards Process Intensification. Sep. Pur. Rev. 2017, 46, 44-61. [CrossRef]

8. Lim, H.G.; Lee, J.H.; Noh, M.H.; Jung, G.Y. Rediscovering Acetate Metabolism: Its Potential Sources and Utilization for Biobased Transformation into Value-Added Chemicals. J. Agric. Food. Chem. 2018, 66, 3998-4006. [CrossRef] 
9. Dhiman, S.S.; Shrestha, N.; David, A.; Basotra, N.; Johnson, G.R.; Chadha, B.S.; Gadhamshetty, V.; Sani, R.K. Producing methane, methanol and electricity from organic waste of fermentation reaction using novel microbes. Bioresour. technol. 2018, 258, 270-278. [CrossRef]

10. Hniman, A.; O-Thong, S.; Prasertsan, P. Developing a thermophilic hydrogen-producing microbial consortia from geothermal spring for efficient utilization of xylose and glucose mixed substrates and oil palm trunk hydrolysate. Int. J. Hyd. Energy 2011, 36, 8785-8793. [CrossRef]

11. Lee, B.D.; Apel, W.A.; DeVeaux, L.C.; Sheridan, P.P. Concurrent metabolism of pentose and hexose sugars by the polyextremophile Alicyclobacillus acidocaldarius. J. Ind. Microbiol. Biotechnol. 2017, 44, 1443-1458. [CrossRef] [PubMed]

12. Zhang, F.; Zhang, Y.; Ding, J.; Dai, K.; van Loosdrecht, M.C.M.; Zeng, R.J. Stable acetate production in extreme-thermophilic $\left(70^{\circ} \mathrm{C}\right)$ mixed culture fermentation by selective enrichment of hydrogenotrophic methanogens. Sci. Rep. 2014, 4, 5268. [CrossRef] [PubMed]

13. Lemos, L.N.; Pereira, R.V.; Quaggio, R.B.; Martins, L.F.; Moura, L.M.S.; da Silva, A.R.; Antunes, L.P.; da Silva, A.M.; Setubal, J.C. Genome-Centric Analysis of a Thermophilic and Cellulolytic Bacterial Consortium Derived from Composting. Front. Microbiol. 2017, 8, 644. [CrossRef] [PubMed]

14. Murali, N.; Fernandez, S.; Ahring, B.K. Fermentation of wet-exploded corn stover for the production of volatile fatty acids. Bioresour. Technol. 2017, 227, 197-204. [CrossRef] [PubMed]

15. Zhou, M.; Yan, B.; Wong, J.W.C.; Zhang, Y. Enhanced volatile fatty acids production from anaerobic fermentation of food waste: A mini-review focusing on acidogenic metabolic pathways. Bioresour. Technol. 2018, 248, 68-78. [CrossRef] [PubMed]

16. Chang, H.N.; Kim, N.-J.; Kang, J.; Jeong, C.M. Biomass-derived volatile fatty acid platform for fuels and chemicals. Biotechnol. Bioproc E. 2010, 15, 1-10. [CrossRef]

17. Wainaina, S.; Lukitawesa; Kumar Awasthi, M.; Taherzadeh, M.J. Bioengineering of anaerobic digestion for volatile fatty acids, hydrogen or methane production: A critical review. Bioengineered. 2019, 10, 437-458. [CrossRef]

18. Ehsanipour, M.; Suko, A.V.; Bura, R. Fermentation of lignocellulosic sugars to acetic acid by Moorella thermoacetica. J. Ind. Microbiol. Biotechnol. 2016, 43, 807-816. [CrossRef]

19. Goswami, V.; Srivastava, A.K. Propionic acid production in an in situ cell retention bioreactor. Appl Microbiol Biotechnol 2001, 56, 676-680. [CrossRef]

20. Kleerebezem, R.; van Loosdrecht, M.C.M. Mixed culture biotechnology for bioenergy production. Curr. Opin. Biotechnol. 2007, 18, 207-212. [CrossRef]

21. Eryildiz, B.; Lukitawesa; Taherzadeh, M.J. Effect of pH, Substrate Loading, oxygen, and Methanogens Inhibitors on Volatile Fatty Acid (VFA) Production from Citrus Waste by Anaerobic Digestion. Bioresour. Technol. 2020, 122800. [CrossRef] [PubMed]

22. Singh, V.; Haque, S.; Niwas, R.; Srivastava, A.; Pasupuleti, M.; Tripathi, C.K.M. Strategies for Fermentation Medium Optimization: An In-Depth Review. Front. Microbiol. 2017, 7, 2087. [CrossRef]

23. David, A.; Singh Chauhan, P.; Kumar, A.; Angural, S.; Kumar, D.; Puri, N.; Gupta, N. Coproduction of protease and mannanase from Bacillus nealsonii PN-11 in solid state fermentation and their combined application as detergent additives. Int. J. Biol. Macromol. 2018, 108, 1176-1184. [CrossRef] [PubMed]

24. Shang, Y.-h.; Zeng, Y.-j.; Zhu, P.; Zhong, Q.-p. Acetate metabolism of Saccharomyces cerevisiae at different temperatures during lychee wine fermentation. Biotechnol. Biotechnol. Equip. 2016, 30, 512-520. [CrossRef]

25. Palma, M.; Guerreiro, J.F.; Sá-Correia, I. Adaptive Response and Tolerance to Acetic Acid in Saccharomyces cerevisiae and Zygosaccharomyces bailii: A Physiological Genomics Perspective. Front. Microbiol. 2018, 9, 274. [CrossRef] [PubMed]

26. Spagnuolo, M.; Shabbir Hussain, M.; Gambill, L.; Blenner, M. Alternative Substrate Metabolism in Yarrowia lipolytica. Front. Microbiol. 2018, 9, 1077. [CrossRef] [PubMed]

27. Schwartz, R.D.; Keller, F.A. Isolation of a Strain Clostridium thermoaceticum Capable of Growth and Acetic Acid Production at pH 4.5. Appl. Environ. Microbiol. 1982, 43, 117. [CrossRef]

28. Leone, S.; Sannino, F.; Tutino, M.L.; Parrilli, E.; Picone, D. Acetate: Friend or foe? Efficient production of a sweet protein in Escherichia coli BL21 using acetate as a carbon source. Microb. Cell. Fact. 2015, 14, 106. [CrossRef]

29. Ledesma-Amaro, R.; Nicaud, J.-M. Metabolic Engineering for Expanding the Substrate Range of Yarrowia lipolytica. Trends Biotechnol. 2016, 34, 798-809. [CrossRef] 
30. Aristidou, A.; Penttilä, M. Metabolic engineering applications to renewable resource utilization. Curr. Opin. Biotechnol. 2000, 11, 187-198. [CrossRef]

31. Shi, S.; Zhao, H. Metabolic Engineering of Oleaginous Yeasts for Production of Fuels and Chemicals. Front. Microbiol. 2017, 8, 2185. [CrossRef] [PubMed]

32. Taskin, M.; Saghafian, A.; Aydogan, M.N.; Arslan, N.P. Microbial lipid production by cold-adapted oleaginous yeast Yarrowia lipolytica B9 in non-sterile whey medium. Biofuels. Bioprod. Bior. 2015, 9, 595-605. [CrossRef]

33. Zhang, H.; Zhang, L.; Chen, H.; Chen, Y.; Chen, W.; Song, Y.; Ratledge, C. Enhanced lipid accumulation in the yeast Yarrowia lipolytica by over-expression of ATP: Citrate lyase from Mus musculus. J. Biotechnol. 2014, 192. [CrossRef] [PubMed]

34. Blazeck, J.; Hill, A.; Jamoussi, M.; Pan, A.; Miller, J.; Alper, H.S. Metabolic engineering of Yarrowia lipolytica for itaconic acid production. Metab. Eng. 2015, 32, 66-73. [CrossRef]

35. Tomaszewska, L.; Rywinska, A.; Gladkowski, W. Production of erythritol and mannitol by Yarrowia lipolytica yeast in media containing glycerol. J. Ind. Microbiol Biotechnol. 2012, 39, 1333-1343. [CrossRef]

36. Cavallo, E.; Charreau, H.; Cerrutti, P.; Foresti, M.L. Yarrowia lipolytica: A model yeast for citric acid production. FEMS Yeast Res. 2017, 17. [CrossRef]

37. Kildegaard, K.R.; Adiego-Pérez, B.; Doménech Belda, D.; Khangura, J.K.; Holkenbrink, C.; Borodina, I. Engineering of Yarrowia lipolytica for production of astaxanthin. Synth. Syst. Biotechnol. 2017, 2, 287-294. [CrossRef]

38. Rigouin, C.; Lajus, S.; Ocando, C.; Borsenberger, V.; Nicaud, J.M.; Marty, A.; Avérous, L.; Bordes, F. Production and characterization of two medium-chain-length polydroxyalkanoates by engineered strains of Yarrowia lipolytica. Microb. Cell. Fact. 2019, 18, 99. [CrossRef]

39. Huang, X.; Lu, X.; Li, Y.; Li, X.; Li, J.J. Improving itaconic acid production through genetic engineering of an industrial Aspergillus terreus strain. Microb. Cell. Fact. 2014, 13, 119. [CrossRef]

40. David, A.; Govil, T.; Tripathi, A.; McGeary, J.; Farrar, K.; Sani, R. Thermophilic Anaerobic Digestion: Enhanced and Sustainable Methane Production from Co-Digestion of Food and Lignocellulosic Wastes. Energies 2018, 11, 2058. [CrossRef]

41. Rice, E.W.; Bridgewater, L. Standard Methods for the Examination of Water and Wastewater; American Public Health Association: Washington, DC, USA, 2012.

42. Sluiter, A.; Hames, B.; Ruiz, R.; Scarlata, C.; Sluiter, J.; Templeton, D.; Crocker, D. Determination of Structural Carbohydrates and Lignin in Biomass; National Renewable Energy Laboratory: Denver West Parkway, Golden, CO, USA, 2008.

43. Haider, M.R.; Zeshan; Yousaf, S.; Malik, R.N.; Visvanathan, C. Effect of mixing ratio of food waste and rice husk co-digestion and substrate to inoculum ratio on biogas production. Bioresour. Technol. 2015, 190, 451-457. [CrossRef] [PubMed]

44. Aydar, A. Utilization of Response Surface Methodology in Optimization of Extraction of Plant Materials, 3rd ed.; BoD-Books on Demand: Norderstedt, Germany, 2018; pp. 157-169. [CrossRef]

45. Montgomery, D.C. Des. and Analysis of Experiments; John Wiley \& Sons, Inc., 2006, 3rd ed. Available online: https://books.google.com.ph/books?hl=zhCN\&lr=\&id=Py7bDgAAQBAJ\&oi=fnd\&pg=PA1\&ots= X6x1mZRN13\&sig=AaBSC8nWvHWxar7TaIc_n_JtRYA\&redir_esc=y\#v=onepage\&q\&f=false (accessed on 7 January 2020).

46. Lukitawesa; Patinvoh, R.J.; Millati, R.; Sárvári-Horváth, I.; Taherzadeh, M.J. Factors influencing volatile fatty acids production from food wastes via anaerobic digestion. Bioengineered. 2020, 11, 39-52. [CrossRef] [PubMed]

47. Strang, O.; Ács, N.; Wirth, R.; Maróti, G.; Bagi, Z.; Rákhely, G.; Kovács, K.L. Bioaugmentation of the thermophilic anaerobic biodegradation of cellulose and corn stover. Anaerobe. 2017, 46, 104-113. [CrossRef] [PubMed]

48. Ali Shah, F.; Mahmood, Q.; Maroof Shah, M.; Pervez, A.; Ahmad Asad, S. Microbial Ecology of Anaerobic Digesters: The Key Players of Anaerobiosis. Sci. World J. 2014, 2014, 183752. [CrossRef] [PubMed]

49. Saha, S.; Jeon, B.-H.; Kurade, M.; Chatterjee, P.; Chang, S.; Markkandan, K.; Salama, E.-S.; Govindwar, S.; Roh, H.-S. Microbial acclimatization to lipidic-waste facilitates the efficacy of acidogenic fermentation. Chem. Eng. J. 2019, 358, 188-196. [CrossRef]

50. Dahiya, S.; Mohan, S.V. Selective control of volatile fatty acids production from food waste by regulating biosystem buffering: A comprehensive study. Chem. Eng. J. 2019, 357, 787-801. [CrossRef] 
51. Yuan, Q.; Sparling, R.; Oleszkiewicz, J.A. VFA generation from waste activated sludge: Effect of temperature and mixing. Chemosphere. 2011, 82, 603-607. [CrossRef]

52. Zinder, S.H.; Anguish, T.; Cardwell, S.C. Selective inhibition by 2-bromoethanesulfonate of methanogenesis from acetate in a thermophilic anaerobic digestor. Appl. Environ. Microbiol. 1984, 47, 1343-1345. [CrossRef]

53. Chidthaisong, A.; Conrad, R. Specificity of chloroform, 2-bromoethanesulfonate and fluoroacetate to inhibit methanogenesis and other anaerobic processes in anoxic rice field soil. Soil Biol. Biochem. 2000, 32, 977-988. [CrossRef]

54. Omar, B.; Abou-Shanab, R.; El-Gammal, M.; Fotidis, I.A.; Kougias, P.G.; Zhang, Y.; Angelidaki, I. Simultaneous biogas upgrading and biochemicals production using anaerobic bacterial mixed cultures. Water. Res. 2018, 142, 86-95. [CrossRef]

55. Nakae, T.; Elliott, J.A. Volatile Fatty Acids Produced by Some Lactic Acid Bacteria. I. Factors Influencing Production of Volatile Fatty Acids from Casein Hydrolysate1. J. Dairy Sci. 1965, 48, 287-292. [CrossRef]

56. Lins, P.; Illmer, P. Effects of volatile fatty acids, ammonium and agitation on thermophilic methane production from biogas plant sludge in lab-scale experiments. Folia. Microbiol. 2012, 57, 313-316. [CrossRef] [PubMed]

57. Xu, F.; Li, Y. Solid-state co-digestion of expired dog food and corn stover for methane production. Bioresour. Technol. 2012, 118, 219-226. [CrossRef] [PubMed]

58. Liu, N.; Jiang, J.; Yan, F.; Xu, Y.; Yang, M.; Gao, Y.; Aihemaiti, A.; Zou, Q. Optimization of simultaneous production of volatile fatty acids and bio-hydrogen from food waste using response surface methodology. RSC. Adv. 2018, 8, 10457-10464. [CrossRef]

59. Jiang, J.; Zhang, Y.; Li, K.; Wang, Q.; Gong, C.; Li, M. Volatile fatty acids production from food waste: Effects of $\mathrm{pH}$, temperature, and organic loading rate. Bioresour. Technol. 2013, 143, 525-530. [CrossRef]

60. Wang, K.; Yin, J.; Shen, D.; Li, N. Anaerobic digestion of food waste for volatile fatty acids (VFAs) production with different types of inoculum: Effect of pH. Bioresour. Technol. 2014, 161, 395-401. [CrossRef]

61. Liu, X.; Liu, H.; Chen, Y.; Du, G.; Chen, J. Effects of organic matter and initial carbon-nitrogen ratio on the bioconversion of volatile fatty acids from sewage sludge. J. Chem. Technol. Biotechnol. 2008, 83, 1049-1055. [CrossRef]

62. Wang, X.; Lu, X.; Li, F.; Yang, G. Effects of Temperature and Carbon-Nitrogen (C/N) Ratio on the Performance of Anaerobic Co-Digestion of Dairy Manure, Chicken Manure and Rice Straw: Focusing on Ammonia Inhibition. PLoS ONE 2014, 9, e97265. [CrossRef]

63. Gao, R.; Li, Z.; Zhou, X.; Cheng, S.; Zheng, L. Oleaginous yeast Yarrowia lipolytica culture with synthetic and food waste-derived volatile fatty acids for lipid production. Biotechnol. Biofuels. 2017, 10, 247. [CrossRef]

64. Rodrigues, G.; Pais, C. The Influence of Acetic and Other Weak Carboxylic Acids on Growth and Cellular Death of the Yeast Yarrowia lipolytica. Food. Technol. Biotechnol. 2000, 12, 579-1006.

65. Wang, Y.; Zhang, Y.; Wang, J.; Meng, L. Effects of volatile fatty acid concentrations on methane yield and methanogenic bacteria. Biomass. Bioenergy 2009, 33, 848-853. [CrossRef]

66. Siegert, I.; Banks, C. The effect of volatile fatty acid additions on the anaerobic digestion of cellulose and glucose in batch reactors. Proc. Biochem. 2005, 40, 3412-3418. [CrossRef]

67. Angelidaki, I.; Ellegaard, L.; Ahring, B.K. A mathematical model for dynamic simulation of anaerobic digestion of complex substrates: Focusing on ammonia inhibition. Biotechnol. Bioeng. 1993, 42, 159-166. [CrossRef] [PubMed]

(C) 2020 by the authors. Licensee MDPI, Basel, Switzerland. This article is an open access article distributed under the terms and conditions of the Creative Commons Attribution (CC BY) license (http://creativecommons.org/licenses/by/4.0/). 